\title{
A EDUCAÇÃO COMO MEIO DE INCLUSÃO SOCIAL
}

\author{
Adriana Lima Neves Vieira ${ }^{1}$ \\ Elaine Luisa Ribeiro ${ }^{2}$ \\ Flavia Cristina Silva ${ }^{3}$ \\ Marly Pedro 4
}

\begin{abstract}
RESUMO: A educação é um direito social, essencial para a dignidade da pessoa humana, consagrada na Constituição Federal no art. 205. Portanto, o presente artigo tem como objetivo levantar a importância de uma educação com qualidade que vise a inclusão social do cidadão, aprimorar suas habilidades e competências para formação de sujeitos de direitos, com consciência crítica, participativos, reflexivos, ético-político e analítico-propositivo. Trata-se de um estudo fundamentado em pesquisa bibliográfica, por meio de livros, documentos, revistas e meio eletrônico. O estudo proporcionou uma reflexão acerca do compromisso da sociedade civil, do Estado, dos profissionais da educação, das famílias em transformar a práxis educacional, oferecer novos paradigmas a educação, para que o ato de educar não fique restrito a repassar conhecimentos e sim em formar cidadãos que busquem a transformação societária, justiça social, democracia e cidadania.
\end{abstract}

PALAVRAS-CHAVES: Educação. Cidadania. Inclusão Social.

\section{INTRODUÇÃO}

A educação na contemporaneidade assume um papel centralizador no que se referem às lutas sociais. Na concepção de Almeida (2008), de fato a educação tem ocupado um lugar central no âmbito das lutas sociais voltadas para a superação da sociedade do capital e das formas de opressão que lhes são características, assim como na agenda intelectual e política de um leque bastante amplo de educadores e cientistas sociais.

A educação, especificamente a educação escolar, é um campo de trabalho permeado por questões complexas que requer diferentes saberes e especializações para respondê-las. Sendo assim não é correto afirmar que este espaço marcado por conflitos sociais que se estendem no interior dos estabelecimentos educacionais mais tradicionais como a escola seja exclusiva da atuação

\footnotetext{
${ }^{1}$ Universidade de Uberaba.

${ }^{2}$ Universidade de Uberaba.

${ }^{3}$ Pos-Graduanda em Gestão Pública em Serviço de Saúde pela Fij.

${ }^{4}$ Assistente Social
} 
[...] de um determinado profissional, quando na verdade seu efetivo enfrentamento requer, na atualidade, não só a atuação dos assistentes sociais, mas um conjunto mais amplo de profissionais especializados (ALMEIDA, 2008, p.89).

A ação do Serviço Social deve apoiar-se como agente de ligação entre a família, a comunidade e a escola para dar unidade à ação educacional, criando um conjunto de medidas de atendimento às famílias, ou aos novos "arranjos familiares" através do provimento de necessidades básicas para a garantia dos direitos sociais.

Direta ou indiretamente, a prática escolar é influenciada por condicionantes históricos, políticos e sociais que implicam em diferentes concepções de homem, mundo, cultura e sociedade.

Conseqüentemente, estas concepções influenciam no conceito de conhecimento, educação, escola e ensino-aprendizagem, que por sua vez apresentarão diversas formas de enxergar o professor, o aluno, os métodos de ensino e a avaliação. Tais concepções também afetarão diretamente a legislação que rege a educação em cada um destes momentos.

O momento histórico que estamos vivendo clama por uma educação que tenha como eixo norteador a formação para o exercício pleno da cidadania.

Covre (1995) enfatiza sobre cidadania:

As pessoas tendem a pensar a cidadania apenas em termos dos direitos a receber, negligenciando o fato de que elas próprias podem ser o agente da existência desses direitos. Acabam por relevar os deveres que Ihes cabem, omitindo-se no sentido de serem também, de alguma forma, parte do governo, ou seja, é preciso trabalhar para conquistar esses direitos. Em vez de meros receptores, são acima de tudo sujeitos daquilo que podem conquistar.

Sendo assim, é essencial que o Poder Público, através da legislação, proponha diretrizes que visem à melhoria do processo educativo, garantindo não só a aprendizagem do aluno, mas a capacidade de aplicar os conhecimentos adquiridos nas diversas situações da vida cotidiana.

Segundo Dimenstein (1993): 
Cidadania é o direito e ter idéia e poder expressa-la. É poder votar em quem quiser sem constrangimento. É processar um médico que cometa um erro. É devolver, um produto estragado e receber o dinheiro de volta. È o direito de ser negro sem ser discriminado, de praticar uma religião sem ser perseguido. (p.20.)

A educação deve criar nos indivíduos a capacidade de compreender os seus direitos diante dos problemas que afligem a sociedade contemporânea e a capacidade de desempenhar ações que permitam reverter esta situação em prol de uma sociedade mais justa e comprometida com o bem comum.

\section{EDUCAÇÃO DE QUALIDADE: DIREITO DE TODOS}

Deve-se, investir na quantidade, ou seja, garantir que o maior número possível de crianças e adolescentes freqüentem a escola, mas investir principalmente na qualidade, para que de fato ocorra a aprendizagem capaz de levar o aluno à emancipação e à humanização, conforme afirma Vallejo (2002, p. 79):

fazer no final o processo, a esperança do educador e do educando é a consecução ou pelo menos a aproximação da meta desejada, que sempre será um modo de ser mais valioso, mais humano, segundo o modelo ou padrão escolhido. A herança biológica nos dá o ser, mas não o modo de ser, pois nascemos humanos, mas não humanizados, sociais, mas não socializados, morais, mas não moralizados [...] Aprendemos a ser humanos, sociais, morais [...] por meio da educação. O nascimento nos dá as capacidades, a educação desenvolve as faculdades e potencialidades que a herança nos proporciona. Esta é a tarefa de toda educação: que a pessoa que nasce aprenda a ser humana, entre os humanos, incorporando valores à sua existência.

Esta tarefa da educação não é atribuída somente à escola, mas, conforme determina a Constituição Federal em seu artigo 205, é tarefa também da família e da sociedade:

A educação, direito de todos é dever do Estado e da família, será promovida

e incentivada com a colaboração da sociedade, visando ao pleno 
desenvolvimento da pessoa, seu preparo para o exercício da cidadania e sua qualificação para o trabalho.

Sendo direito do cidadão, a Lei de Diretrizes e Bases da Educação - LDB - é o mecanismo legal que regulamenta a educação no país, garantindo que o direito assegurado na Constituição Federal se efetive na prática. A própria LDB, em seu artigo $1^{\circ}$, ressalta a participação da família e da sociedade na educação ao afirmar que:

A educação abrange os processos formativos que se desenvolvem na vida familiar, na convivência humana, no trabalho, nas instituições de ensino e pesquisa, nos movimentos sociais e organizações da sociedade civil e nas manifestações culturais.

Tais considerações permitem inferir que a educação é tarefa coletiva, delegada ao Poder Público, à família e à sociedade em geral.

A atual legislação educativa do Brasil foi aprovada em dezembro de 1996, sob o número 9394, substituindo a lei anterior n'. 5692/71. A aprovação desta lei que consolidou e ampliou o dever do poder público para com a educação, foi um importante marco na luta pela democratização da educação no país, principalmente se comparada com a lei anterior, criada em pleno regime militar, cujo foco principal era a preparação de trabalhadores servis que atendessem à demanda do mercado de trabalho.

A sociedade atual, ao contrário, clama pela formação do cidadão capaz de atuar criticamente na sociedade através de uma educação libertadora, cuja função é explicitada por Mészaros:

Já a educação libertadora teria como função transformar o trabalhador em um agente político, que pensa que age, e que usa a palavra como arma para transformar o mundo (2005, p. 12).

Vieira (2000), também soube traduzir os anseios da sociedade atual em relação à educação ao afirmar que:

A política educacional que vai responder aos desafios de uma sociedade democrática, contudo, ainda não tomou sua forma. Vive-se um tempo de busca, de ensaios e de grande efervescência na organização da sociedade. 
O velho já não atende às demandas que vão surgindo, o novo, entretanto, ainda não nasceu. De outra parte, essa transição, pressionada pela conjuntura internacional e nacional, contraditoriamente, vem marcada pelo questionamento do Estado como agente que assegura os direitos sociais, expressos nos serviços públicos, inclusive no oferecimento da educação pública (VIEIRA, 2000, p. 20).

Vale ressaltar, entretanto, que embora a Lei 9394/96 tenha sido fruto de muitas discussões, além de ter sido um grande avanço no contexto educacional brasileiro em relação às leis anteriores, ficou diversas lacunas a serem preenchidas.

Sendo assim, a participação da sociedade é essencial tanto para garantir que os preceitos legislativos sejam aplicados como para sinalizar as adequações necessárias em prol de uma educação democrática, cidadã e de qualidade. E é necessário que a educação atenda aos anseios e às necessidades desta população específica que está matriculada na escola, respeitando-se à LDB, que por sua vez reporta-se à Lei Maior, que é a Constituição Federal, vão sendo criados pareceres e resoluções tendo em vista a regulamentação da legislação.

Em consonância com estes marcos legais, foram elaborados os Parâmetros Curriculares Nacionais - PCNs, que têm como objetivo subsidiar a prática dos educadores:

Os Parâmetros Curriculares Nacionais constituem o primeiro nível de concretização curricular. São uma referência nacional para o ensino fundamental; estabelecem uma meta educacional para a qual devem convergir as ações políticas do Ministério da Educação e do Desporto, tais como os projetos ligados à sua competência na formação inicial e continuada de professores, à análise e compra de livros e outros materiais didáticos e à avaliação nacional. Têm como função subsidiar a elaboração ou a revisão curricular dos Estados e Municípios, dialogando com as propostas e experiências já existentes, incentivando a discussão pedagógica interna das escolas e a elaboração de projetos educativos, assim como servir de material de reflexão para a prática de professores. (BRASIL, PCNs-INTRODUÇÃO, 2001, p. 36).

As diretrizes curriculares são, portanto proposições de caminhos abertos à tradução em diferentes programas de ensino, a serem elaborados, no contexto local, conforme a sua realidade. Vale lembrar, entretanto, que mesmo com uma diretriz 
curricular, a realidade educacional brasileira compõe-se de muitos desafios a serem vencidos para uma construção de uma proposta pedagógica inovadora.

Enriquecendo as diretrizes curriculares que se referem aos diversos conteúdos curriculares, foram elaboradas as diretrizes referentes aos temas transversais, que são temas considerados de urgência nacional e/ou local a serem trabalhados em todas as disciplinas, a partir de uma abordagem crítica, buscando atender aos anseios de uma sociedade democrática. Os temas transversais incluem Ética, Meio Ambiente, Saúde, Pluralidade Cultural e Orientação Sexual. Tais temas expressam conceitos e valores fundamentais à democracia e à cidadania e correspondem a questões importantes e urgentes para a sociedade brasileira.

Se resumir em poucas palavras qual a atividade fim da escola, ou seja, o motivo pelo qual a escola existe, poder-se-ia dizer que é a realização do processo ensino/aprendizagem, de forma que este processo resulte em aprendizagem, ou seja, que o aluno que lá está inserido saia de lá modificado. Este processo tem sua culminância na ação do professor e do aluno em torno do conhecimento no interior da sala de aula.

Conforme Harper (1986, p.23):

\begin{abstract}
Antigamente existiam sociedades sem escola. A prática educativa consistia na aquisição de instrumentos de trabalho e na interiorização de valores e comportamentos, enquanto o meio ambiente em seu conjunto era um contexto permanente de formação. Não havia professores. Todo adulto ensinava. Aprendia-se a partir da própria experiência e da experiência dos outros. Aprendia-se fazendo, o que tornava inseparáveis o saber, a vida e o trabalho.
\end{abstract}

Ainda para Harper (1986, p. 26), a partir da Idade Média um conjunto de pessoas especializou-se na transmissão do saber, surgindo assim à escola.

\title{
NOVOS PARADIGMAS PARA EDUCAÇÃO
}

Hoje a instituição escolar consagrou-se praticamente em todo o mundo, e no desenvolvimento deste processo encontramos, além do professor e do aluno, outros profissionais que são co-responsáveis para que a finalidade da escola seja atingida: diretor, supervisor, orientador, inspetor, secretário e demais servidores da escola. 
Todos estes diferentes atores participantes do processo educativo têm uma função específica, mas o mesmo objetivo, cuidar para que de fato a aprendizagem aconteça.

Analisando o modelo de sociedade atual, entretanto, percebemos que diversos desafios são impostos aos educadores, tornando imprescindível que se repense o papel da escola na comunidade.

Segundo Libâneo (2003, p. 19):

\begin{abstract}
A prática escolar consiste na concretização das condições que asseguram a realização do trabalho docente. Tais condições não se reduzem ao estritamente "pedagógico", já que a escola cumpre funções que lhe são dadas pela sociedade concreta que, por sua vez, apresenta-se como constituída por classes sociais com interesses antagônicos. A prática escolar, assim, tem atrás de si condicionantes sociopolíticos que configuram diferentes concepções de homem e de sociedade e, conseqüentemente, diferentes pressupostos sobre o papel da escola, aprendizagem, relação professoraluno, técnicas pedagógicas, etc.
\end{abstract}

A "sociedade concreta", mencionada por Libâneo (2003), possui características mutáveis, sendo que hoje ela caracteriza-se, entre outras coisas, pelo avanço tecnológico, pela mudança na estrutura familiar e pelas influências da sociedade neoliberal. $\mathrm{O}$ avanço tecnológico fez com que o acesso à informação acontecesse de forma muito mais rápida. Conforme Souza Júnior (apud FONSECA, 2007, p. 62):

Grandes transformações estão ocorrendo na nossa sociedade e interferem, direta e indiretamente, nos múltiplos processos educacionais. A disseminação dos computadores na vida cotidiana atual constitui um fato importante, que chega até nossas escolas.

Nesse contexto a escola deixou de ser a principal fonte onde o aluno adquire conhecimento, o que obrigatoriamente deve levar os educadores a reverem sua postura e metodologias diante do ensino. $\mathrm{Na}$ era atual, considerada a Era da Informação, já não há espaço para a pedagogia tradicional em que o professor, através da exposição verbal, impõe o conteúdo aos alunos como verdade absoluta e inquestionável. Sabe-se que muitos professores insistem ainda nesta metodologia, 
mas sabe-se também que a mesma não tem possibilitado ao aluno internalizar conhecimentos essenciais para sua vida.

A alteração no modelo de família também afetou o trabalho escolar. Segundo Lancam (1980, apud BOCK, 1989, p. 143):

A importância da primeira educação é tão grande na formação da pessoa que podemos compará-la ao alicerce da construção de uma casa. Depois, ao longo da sua vida, virão novas experiências que continuarão a construir a casa/indivíduo, relativizando o poder da família.

Entretanto, percebe-se que hoje funções outrora atribuídas à família foram delegadas à escola, que tem que incluir em seu currículo a formação de hábitos e valores básicos que já deveriam ter sido aprendidos no ambiente familiar.

Neste contexto é comum encontrar educadores lastimando e recordando os tempos antigos em que os alunos eram mais disciplinados e a função do professor se restringia à transmissão do conhecimento. Necessário se faz que os educadores compreendam que, apesar das dificuldades, esta é a realidade atual, e é com este aluno concreto que terão que trabalhar, buscando, da melhor forma possível, propiciar ao aluno a aquisição do conhecimento e valores indispensáveis para a vida em sociedade.

Tal situação torna extremamente importante a cumplicidade entre família e escola, visto que ambas têm objetivos em comum. Segundo TIBA (1996, p. 140):

O ambiente escolar deve ser de uma instituição que complemente o ambiente familiar do educando, os quais devem ser agradáveis e geradores de afetos. Os pais e a escola devem ter princípios muito próximos para o benefício do filho/aluno.

Para isso é necessário abrir espaço para a participação das famílias dentro da escola onde se discuta claramente qual o papel de cada uma destas instituições no processo educativo.

A doutrina neoliberal capitalista também influenciou o cotidiano escolar, provocando na sociedade uma inversão de valores. Os jovens, em sua maioria, buscam o prazer imediato, influenciados pelo consumismo, e a aquisição de valores éticos e culturais se encontra em segundo plano. Resgatar estes princípios éticos e 
culturais é função também da escola, que deve preocupar-se com a formação integral dos alunos. Esta tarefa de cuidar de maneira adequada da formação integral de crianças e adolescentes é extremamente difícil, pois requer que os educadores tenham capacidade de trabalhar com os conflitos gerados pela impulsão dos jovens em direção a satisfação rápida, às necessidades bio-psíquico-sociais de cada etapa vivenciada.

Em síntese, esta é a escola atual, que há dezesseis anos já era percebida por Arendt da seguinte forma:

O problema da educação no mundo moderno está no fato de, por sua natureza, não poder esta abrir mão nem da autoridade, nem da tradição, e ser obrigada, apesar disso, a caminhar em um mundo que não é estruturado nem pela autoridade nem tampouco mantido coeso pela tradição (ARENDT, 1997, p. 245).

Alguns educadores conseguem identificar a escola como espaço essencial para a valorização da cultura construída historicamente e socialmente, e, utilizandose de uma prática - conforme Paulo Freire preconizava - mediatizada pelo diálogo e valorização da cultura do aluno - contribuem para fazer da educação uma forma política de transformar a sociedade:

O diálogo não é um produto histórico, é a própria historicização. É ele, pois, o movimento constitutivo da consciência que, abrindo-se para a infinitude, vence intencionalmente as fronteiras da finitude e, incessantemente, busca reencontrar-se ela a si mesma num mundo que é comum; porque é comum esse mundo, buscar-se a si mesma é comunicar-se com o outro. 0 isolamento não personaliza porque não socializa (FREIRE, 1987, p. 16).

Estes educadores, que conseguem perceber o sentido amplo de sua prática, explicitando em seu trabalho suas convicções. Mas muitos ainda não têm um quadro de referência para orientar sua prática, utilizando-se, portanto, para ensinar, ora do senso comum e de experiências por eles vividas na condição de alunos, ora da tendência pedagógica em moda no momento, sem levar em conta o contexto atual, o aluno atual, enfim, o mundo atual que vem se transformando rapidamente.

O momento atual clama por uma nova escola, integrada ao contexto social deste milênio, comprometida com a construção de uma sociedade embasada em 
valores humanos e sociais. O mundo atual precisa de pessoas com uma formação aberta, flexível, solidária, democrática, e, conforme Severino (2001, p.32), pessoas com uma postura de análise detida e de vigilância crítica. Faz-se necessário superar a visão puramente instrumental da educação, passando-se a considerá-la em toda a sua plenitude, levando o aluno a aprender "a aprender", “a ser" e a "a conviver".

A globalização dos conhecimentos vem ao encontro das necessidades de romper com os saberes que se apresentam compartimentalizados, engavetados em disciplinas nos espaços de aprendizagem. Essa situação não combina mais com as novas demandas de aprendizagem na contemporaneidade e exige percepções e encaminhamentos cada vez mais globais e integrados (SILVA, 2007, p. 17).

Estas percepções e encaminhamentos globais e integrados sugeridos por Silva (2007) supõem o diálogo multiprofissional, através da parceria da escola com outras instâncias da sociedade, desenvolvendo assim um trabalho em rede tendo em vista a formação integral das crianças e adolescentes. O sentido de coletividade, portanto, deve estar intrinsecamente associado ao ambiente escolar, ultrapassando, contudo, os muros escolares e se espalhando por toda a sociedade, lembrando que, segundo Ronca (1985, p. 35) "[...] educação é uma tarefa e um encargo coletivo no mundo de hoje".

O trabalho coletivo com toda a comunidade escolar, alunos, pais, educadores e comunidades, ele deve adotar uma postura investigativa e ao mesmo tempo reflexiva contribuindo para a construção de uma escola que atenda às necessidades da sociedade atual.

Não basta que preveja a articulação de ações. Isso de nada valerá se as pessoas a que estas ações estão confiadas não se articularem também, porque é dividindo tarefas por todos e somando os esforços de cada um que se diminui o dispêndio de energias e se multiplica o resultado final (ALVES, 1985, p. 70).

Desta forma, é essencial a promoção de encontro entre os profissionais da escola para que possam se organizar, pensar e discutir as concepções, experiências e problemas inerentes ao processo educativo através da adoção de uma postura 
investigativa frente à prática pedagógica. A escola deve intensificar as discussões sobre as situações-problema a partir de novos questionamentos, a fim de promover a compreensão do fazer pedagógico. As discussões do problema no âmbito coletivo permitem exercitar uma ação pedagógica de forma consciente e reflexiva.

A escola reflexiva será construída na medida em que se socializam as construções individuais dos profissionais envolvidos acerca do processo educativo, discutindo-se no âmbito coletivo as percepções de todos os membros do grupo.

Vale ressaltar que educadores que esperam fórmulas prontas para solucionar os problemas da educação jamais conseguirão adotar uma postura investigativa e reflexiva. Não há como encomendar respostas; elas precisam ser construídas coletivamente através da reflexão sobre os fatos à luz da teoria. Os profissionais que atuam na escola devem ter plena consciência de que a transformação não é fruto de uma tarefa individual e única, mas resultado de um trabalho coletivo.

Este exercício de troca de experiências e de partilha de conhecimentos é um desafio a ser trabalhado dentro da escola. Compartilhar idéias é um exercício a ser praticado diariamente, e envolve saber ouvir, saber respeitar, saber colocar-se no lugar do outro e saber administrarem os conflitos, que também podem constituir-se em fatores de crescimento. Para tanto, é preciso abandonar a resistência diante da mudança, aprender com os próprios erros e avançar em direção a uma construção epistemológica mais consciente.

Assim como os alunos que, devem se inteirar com os pares para construírem seu conhecimento na relação com o outro num trabalho solidário e colaborativo, os educadores também constroem sua práticas pedagógicas em equipe. Para tanto deve haver na escola espaço para todos se expressarem, para socializarem suas experiências, tanto positivas como negativas; para exprimirem suas dúvidas, suas angústias, mas também suas alegrias, seus acertos. Este ambiente colaborativo, sem concorrências e sem medos eleva a auto-estima de todos os envolvidos no processo educacional, e com certeza influencia diretamente nas situações de ensino-aprendizagem, pois não há escola de qualidade sem um ambiente saudável entre professores, alunos, direção e funcionários.

Tendo em vista que a educação é uma política pública de direito constitucional, este, portanto, deve ser garantido não somente com a democratização do acesso do sujeito à educação, mas, sobretudo à qualidade do 
ensino, a fim de promover o crescimento cultural do indivíduo enquanto cidadão (1).

Nesse contexto cabe ao assistente social, por meio de seu exercício profissional, ampliar e contribuir para a garantia de acesso aos direitos previsto na Constituição Federal de 1988. Para realizar o seu trabalho, o profissional do Serviço Social e o psicólogo terão de levar em conta o projeto político-pedagógico das instituições e dos estabelecimentos públicos de ensino. A equipe deverá levar em conta também as necessidades específicas de desenvolvimento do educando partindo inclusive de uma análise da conjuntura local.

Neste universo surgem às demandas para o atendimento dos assistentes sociais, estas recaem em diversas situações que incorrem sobre a necessidade de trabalho com famílias e com as crianças e adolescentes, que se manifestam de forma muito mais intensa e complexa, como:

[...] a juventude e seus processos de afirmação e reconhecimento enquanto categoria social, exacerbadamente, mediado pelo consumo; a ampliação das modalidades e a precoce utilização das drogas pelos alunos; a invasão da cultura e da força do narcotráfico; a pulverização das estratégias de sobrevivência das famílias nos programas sociais; a perda do atrativo social da escola como possibilidade de ascensão social e econômica; a negação da profissionalização da assistência no campo educacional com a expansão do voluntariado; a gravidez na adolescência tomando o formato de problema de saúde pública e a precarização das condições de trabalho docentes são algumas das muitas expressões da questão social (ALMEIDA, 2008, p.89).

Diante de tais necessidades, abre-se, assim, um campo de atuação bastante promissor e estratégico permitindo a estes profissionais atuar na política educacional, com questões que lhes são centrais, como a formação permanente dos educadores e com a ampliação das práticas educacionais, não mais numa perspectiva complementar ou paralela e sim curricular.

\section{CONSIDERAÇÕES FINAIS}

No atual contexto brasileiro, nota-se que o ensino tem se mostrado insuficiente, no que se refere à quantidade de vagas para o atendimento dos alunos, tendo-se como um dos grandes desafios à melhoria de sua qualidade. Com a 
perspectiva de incluir aqueles que se encontram em processo de exclusão social, a escola possibilita aos seus alunos fazerem parte da sociedade em que vivem.

A escola enquanto equipamento social precisa compreender as mais diferentes formas de manifestação de exclusão social as quais possam estar ocorrendo, desde questões que envolvam a violência urbana, atitudes discriminatórias, de etnia, do gênero, de sexo, de classe social, etc., reprovações, até a evasão escolar, que muitas vezes é provocada pela necessidade do aluno de trabalhar para contribuir na renda familiar.

Neste contexto social a escola deixou de ser somente uma instituição responsável pela transmissão de conhecimento, existindo a necessidade de entender todos os aspectos sociais que permeiam a existência do aluno. Tal existência é marcada de conflitos envolvendo a prostituição e o trabalho infantil, as diversas formas de violência, o alcoolismo e o uso de drogas, etc. Sendo assim, é imprescindível a identificação e posterior encaminhamento e atendimento a essas demandas para que o corpo técnico da escola possa dar continuidade em seu trabalho pedagógico.

Portanto, é primordial criar uma rede de atendimento multiprofissional e ao mesmo tempo interdisciplinar no interior da escola, é uma saída para que o aluno possa, além de ter garantido seu direito à educação, também tenha atendido outros direitos básicos que configuram sua existência humana.

Assim a escola é entendida como um espaço de aquisição do conhecimento e também para construção e recriação de propostas solidárias voltadas para a promoção da cidadania e dignidade humana.

\section{REFERÊNCIAS}

ALMEIDA, N. L. T. O. A educação como direito social e a inserção dos assistentes sociais em estabelecimentos educacionais. In: Serviço Social e a política de Educação. CADERNO de Comunicações do $8^{\circ}$ Congresso Brasileiro de Assistentes Sociais. Bahia, 2000.

ALVES, N. (coord.). Educação e Supervisão - O trabalho coletivo na escola. São Paulo: Cortez, 1985. 
ARENDT, H. Entre o passado e o futuro. São Paulo: Perspectivas, 1997.

BRASIL, Constituição da República Federativa do Brasil: Texto constitucional promulgado em 05 de outubro de 1988, com as alterações adotadas pelas Emendas Constitucionais $n^{\circ} 1 / 92$ a 40/2003 e pelas Emendas Constitucionais de Revisão $n^{\circ} 1$ a 6/94, - Brasília: Senado Federal, 2002.

Parâmetros Curriculares Nacionais: Introdução aos parâmetros Curriculares Nacionais, Ministério da Educação, Secretaria da Educação Fundamental, 3Ed., Brasília-DF, 2001.

COVRE, Maria de Lourdes Manzini. O que é cidadania. Edição Brasilense. $3^{\circ}$ ed. 1995.

DIDONET, V. Desafios legislativos na revisão da LDB: alguns aspectos gerais e itens sobre a educação infantil. Disponível em: <http://www.omep.org.br/adesafios. pdf.> Acesso: 11 Nov.2009.

DIMENSTEIN, GILBERTO. O cidadão de papel. São Paulo: Ática, 1993.

FREIRE, P. Pedagogia do oprimido. Rio de Janeiro: Paz e Terra, 1987.

HARPER, B. et al. Cuidado, Escola!. São Paulo, Brasiliense, 1986.

LIBÂNEO, J. C. Democratização da escola pública: a pedagogia crítico-social dos conteúdos. São Paulo: Loyola, 2003.

MÉSZÁROS, I., A educação para além do capital, Tradução: Isa Tavares, São Paulo, Boitempo, 2005.

PEREIRA, T. S. "Famílias possíveis: novos paradigmas na convivência familiar", in Afeto, ética, família e o novo código civil brasileiro. Rodrigo da Cunha Pereira (Org.). Belo Horizonte: IBDFAM/Del Rey, 2004. 
RONCA, A. C. C.; GONÇALVES, C. L. A Supervisão escolar: um urgente deságio. In: ALVES, Nilda (coord.). Educação e Supervisão - 0 trabalho coletivo na escola. São Paulo: Cortez, 1985.

SILVA, R. M. G.; BRITO, F. R. Ensino de Ciências e Geografia. Dos movimentos fragmentários à compreensão globalizada do conhecimento escolar. In: FONSECA, Selva Guimarães. Currículos, saberes e culturas escolares. Campinas: Alínia, 2007.

SOUZA JUNIOR, A. J. Informática e Cultura Profissional: o laboratório de informática da escola como espaço de formação. In: FONSECA, Selva Guimarães. Currículos, saberes e culturas escolares. Campinas: Alínia, 2007.

TIBA, I. Disciplina, limite na medida certa. São Paulo: Gente, 1996.

VIEIRA, S, L. Política Educacional em Tempo de Transição: 1985 -1995 BRASÍLIA: Plano, 2000.

Recebido para publicação em: 30/10/2010

Aceito: 20/12/2010 